\title{
Application of 3D Visualization in Landscape Design Teaching
}

\author{
https://doi.org/10.3991/ijet.v14i06.10156 \\ Wenbo Jiang $(\bowtie)$ \\ Hebei University of Environmental Engineering, Qinhuangdao, China \\ 305898103@qq.com \\ Yuan Zhang \\ Qinhuangdao Institute of Technology, Qinhuangdao, China
}

\begin{abstract}
The development of computer technology has reshaped the form and philosophy of landscape design, as evidenced by the growing importance of computer-aided design (CAD) in this area. This paper attempts to apply $3 \mathrm{D}$ visualization in the teaching of landscape design. For this purpose, three CAD teaching tools were selected, namely, AutoCAD, 3D Max and SketchUp, and subjected to theoretical analysis and teaching practice. The research results show that AutoCAD can guide the landscape design teaching from conception to positioning, 3D Max can upgrade the teaching form from 2D to 3D in the later phase, and SketchUp supports the entire process of landscape design. In addition, the author summarized the specific process of supporting landscape design teaching with SketchUp. This research enriches the results on the application of $\mathrm{CAD}$ in landscape design teaching and has certain theoretical and practical significance.
\end{abstract}

Keywords - Computer aided design (CAD), landscape design, theoretical teaching, practical teaching

\section{Introduction}

With the continuous development of computer science and the Internet, computers have become powerful tools in the information age, driving the rapid development of various industries. Taking the landscape design for instance, computers have been widely adopted to improve the design efficiency. The designers are enabled to display their ideas in vivid graphics, and make continuous analysis and modifications to the design plan [1]. The computer-aided design (CAD) plays a pivotal role in landscape design, heralding a revolution of the design forms and concepts. The mastery of CAD software has become a required skill for every landscape designer [2]. Therefore, the landscape design teaching must help students gain proficiency of CAD software.

The first computer-aided drawing system appeared in the 1950s [3], followed by the emergence of CAD surface patch technology in the 1960s. The CAD technology became increasingly standardized, integrated and intelligent in the 1980s [4]. In 1996, 
3D Studio MAX 1.0 (3D MAX), the first Windows version of 3D Studio series, came into being. Being a PC-based software for 3D animation rendering and production, 3D MAX has been widely used in architectural design. Industrial design, auxiliary teaching and other fields [5-8]. Another popular and easy-to-use 3D design software is SketchUp. The software helps designers make intuitive expression of their ideas on computers. Targeting the creation of the design plan, SketchUp is hailed by many as the stylus of architect and the trump card of aided design [9].

Despite the rapid advancement in CAD, the college courses on CAD software are still in their infancy. The current $\mathrm{CAD}$ teaching mode faces many problems, such as the irrational arrangement of courses and the lack of diverse teaching methods [10]. To solve the problems, the educational circle should reform the teaching mode of CAD software, such that the students can master the software operations, use the software in landscape design and satisfy the social demand for landscape design. Nevertheless, the existing studies [11] mostly concentrate on the application of CAD software in different design projects. There is no systematic research on the application results of CAD software in landscape design teaching.

In light of the above, this paper explores the application of CAD in the theoretical and practical teachings of landscape design. For theoretical teaching, the author briefly introduced the teaching functions of three popular CAD software for landscape design, namely, AutoCAD, 3D MAX and SketchUp. For practical teaching, the author analyzed the application of SketchUp teaching software in practical teaching of landscape design, and summed up the specific operation procedure. Meanwhile, some suggestions were put forward on the teaching method for CAD software.

\section{Application of CAD Software in Theoretical Teaching of Landscape Design}

\subsection{AutoCAD teaching software}

The CAD software AutoCAD is the most basic software of landscape design. The software guides the whole process from conception to positioning, facilitating the teaching from early conceptual design to function design [12]. It is known for good compatibility, strong data exchangeability, as well as powerful graphic editing and drawing functions. Besides drawing the floor plan, AutoCAD offers auxiliary tools to capture the key points of many operation interfaces, and provides secondary editing tools for rotation, duplication and array, which are frequently used for rendering in landscape design.

With user-friendly interfaces and easy-to-run commands and menus, AutoCAD allows the operator to draw images through the menus or command lines. A learner can easily get familiar with and master the software. The AutoCAD course in most Chinese colleges lasts 36 hours, which is sufficiently long to satisfy the teaching objective. However, the teacher should not stop at explaining the basic operational commands of AutoCAD. Instead, the software should be integrated into landscape design, 
so that the students can learn how to operate and apply it in actual projects and scenes. Figure 1 presents the CAD landscape design plan for a duplex with courtyard.

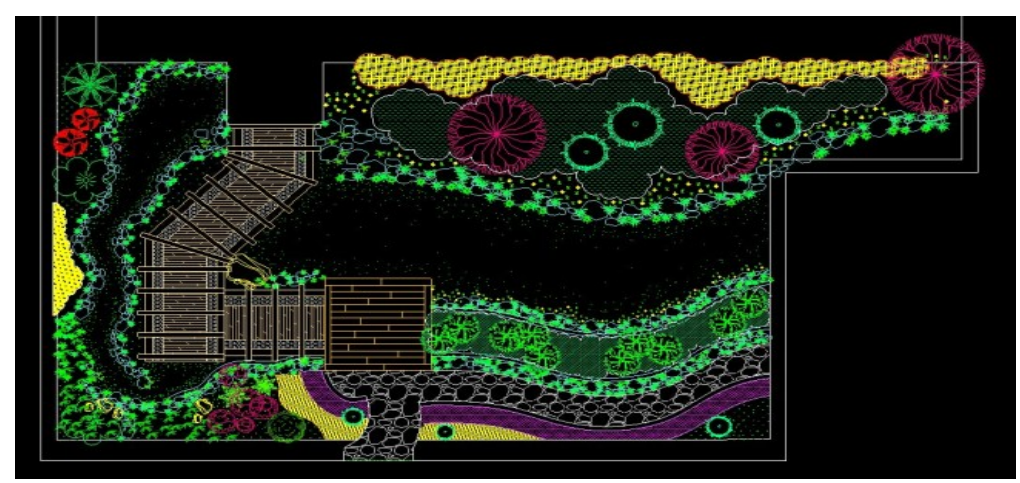

Fig. 1. Double-family villa courtyard cad landscape design

\subsection{D MAX teaching software}

3D MAX is a drawing software combining such functions as modeling, texture modification, material, rendering, animation and lighting. It is one of the most important learning software in landscape design teaching. As a powerful 3D modeling tool, 3D Max can upgrade the teaching form from 2D to 3D in the later phase [13].

3D MAX teaching software has a great significance in landscape design teaching. The teacher should focus on the teaching and training of basic operational commands, the operation and training of common operational commands, the editing and training of $2 \mathrm{D}$ patterns, and the teaching and training of 3D space capabilities, as well as teaching and training of texture and lighting visualization. Figures 2 and 3 are respectively the lighting operation interface and micro terrain rendering of 3D MAX.

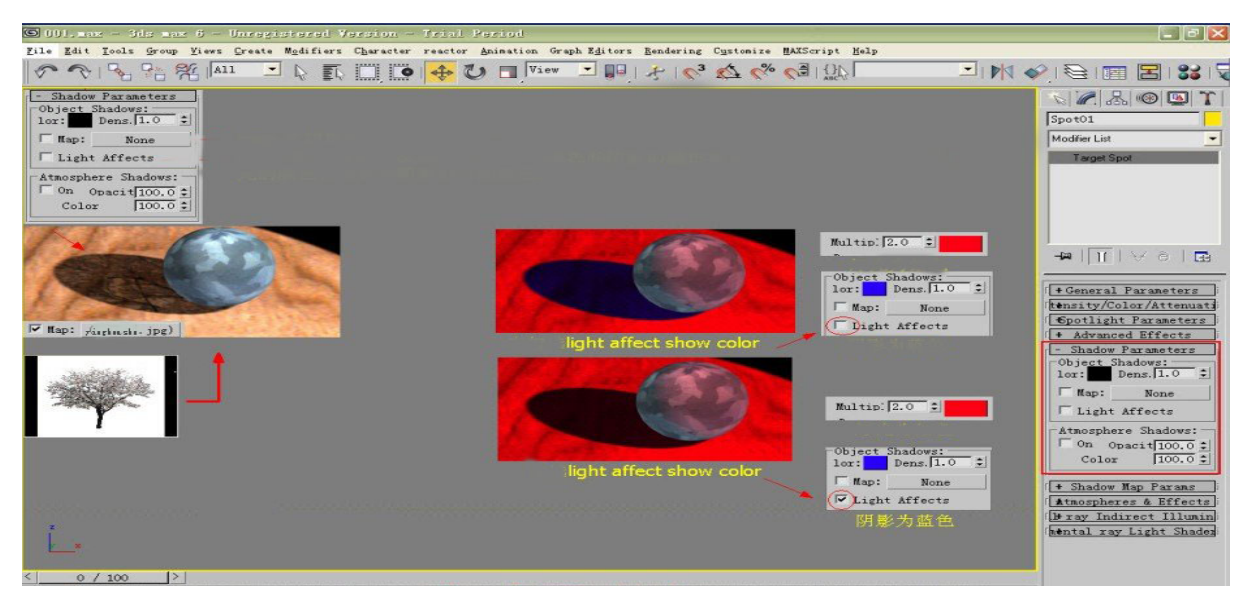

Fig. 2. 3D MAX light operation interface 


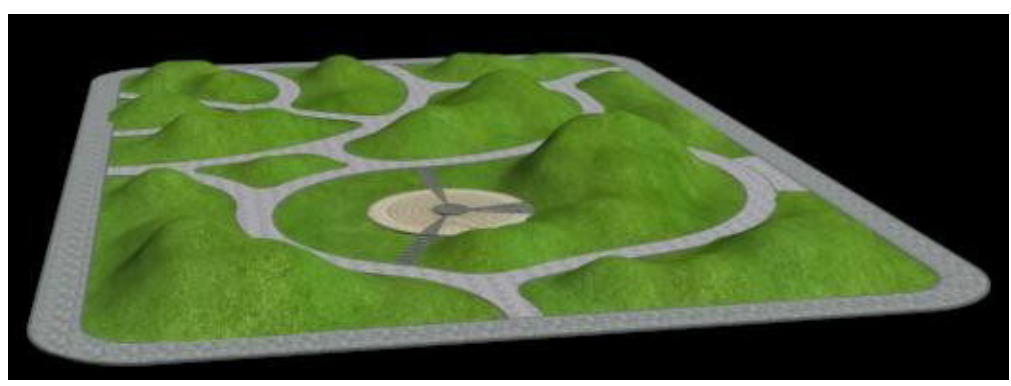

Fig. 3. 3D MAX micro terrain production effect

\subsection{SketchUp teaching software}

SketchUp, praised as sketch design master, is the most popular sketch design tool in landscape design. With the aid of SketchUp, the user can design lots of sketches rapidly, as if he/she is drawing with pen and paper. The sketches all carry a refreshing sense of design. There are many advantages of SketchUp. The software is directly oriented to the design process, and provides the designer with a $3 \mathrm{D}$ design environment (Figure 4) and real-time rendered scenes (Figure 5). Thus, the entire process of landscape design, from the analytical thinking to the design plan, can be completed within the software.

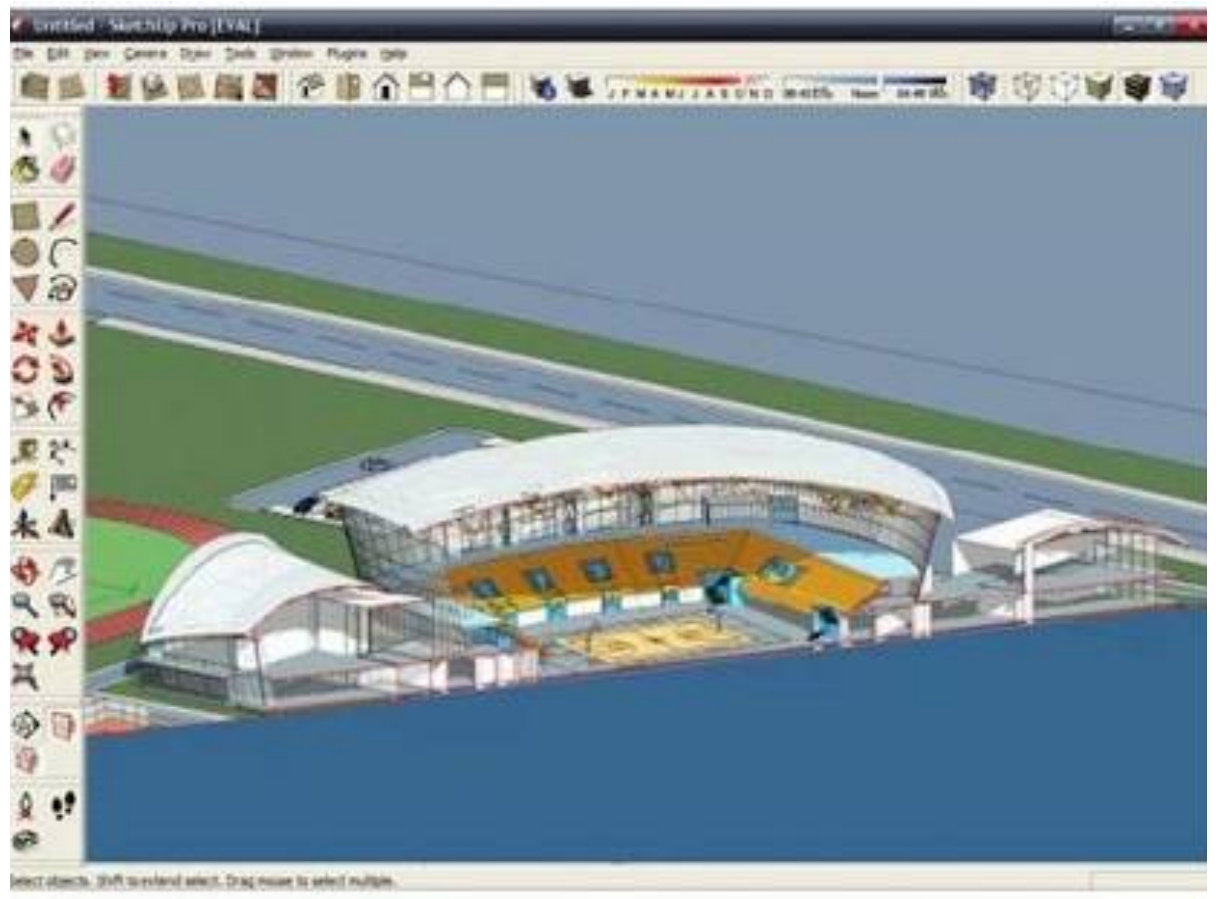

Fig. 4. Three-dimensional operation 


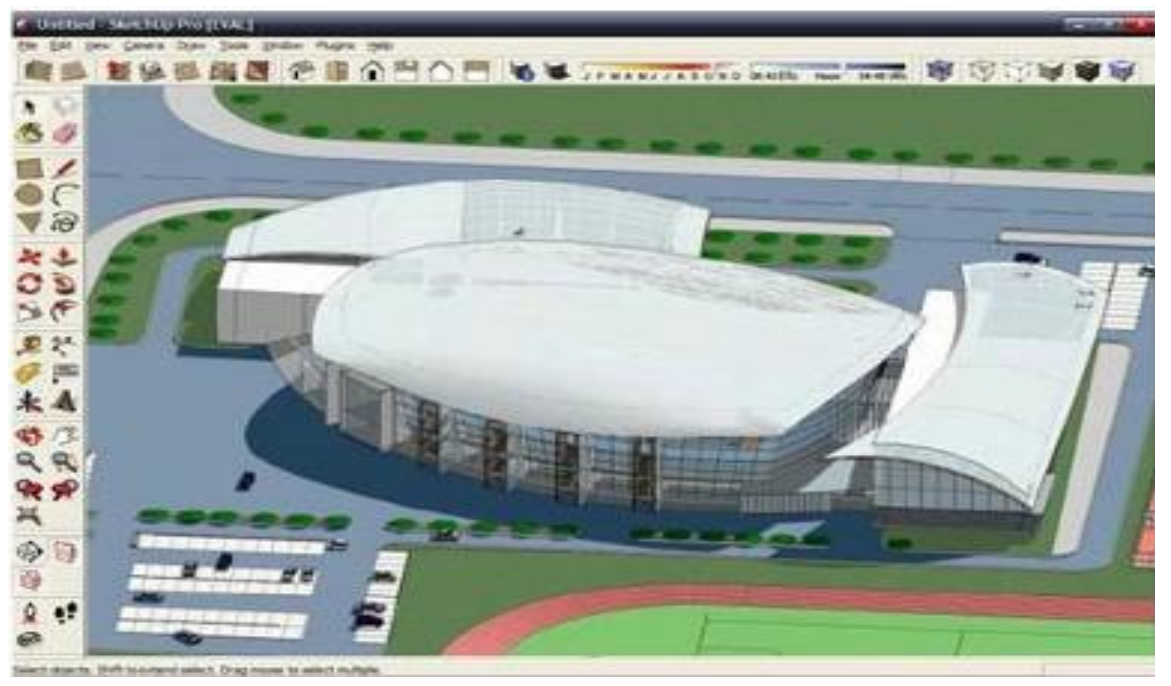

Fig. 5. Real-time rendering of the model

The SketchUp facilitates personalized operations and improves work efficiency, thanks to its intuitive and simple interfaces, convenient and fast operation tools and customizable shortcuts to all commands. To make students master and apply SketchUp, the teacher should highlight the understanding and application of basic concepts like pages, views, axes, groups and components.

\section{Groups and components:}

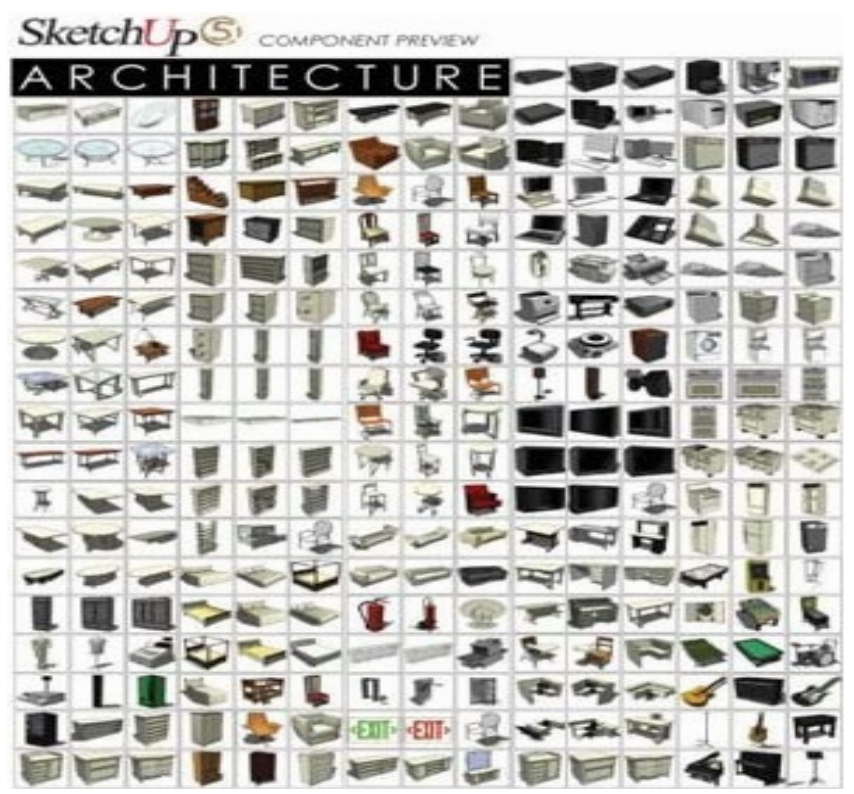

Fig. 6. Groups and components 
As shown in Figure 6, groups and components are the basic units for drawing. The groups can be set up like the definition of blocks in AutoCAD. The components are very similar to groups, except that they have the correlation function [14]. Any model can be inserted as a component into another model.

Views: SketchUp can generate various views, such as plane, elevation and profile. Moreover, the same view can be represented differently to meet the specific requirements on visualization. A view environment must be selected when the landscape design model is established. Otherwise, the design model cannot be expressed.

Pages: SketchUp can present multiple pages in the same viewport to display the scene from a specific viewpoint while comparing the scenes from multiple angles. In addition, the pages can be played in an animated manner, offering a dynamic view of the design results [2].

\section{Application of CAD Software in Practical Teaching of Landscape Design}

\subsection{Teaching overview}

Garden design, an important topic of landscape design, has been highlighted in the development of modern real estate, parks and squares. SketchUp can satisfy the needs of the design of garden landscape with a rich set of landscape design components.

Here, the project teaching and situational teaching are combined into the practical teaching of SketchUp-aided landscape design [4]. Before the teaching, the students received the project chapter and paid field visit to the project site. In this way, they had the specific ideas of garden landscape. After that, the teacher introduced the tools, terms and abilities of SketchUp and the roles of the software in garden landscape design.

\subsection{Application process of SketchUp in landscape design}

After students understood the specific application of SketchUp in garden landscape design, the teacher summed up the landscape design procedure of an actual design project of garden landscape [8] (Figure 7), and asked the students to complete actual tasks of SketchUp-aided landscape design. The design procedure can be summarized as follows:

Field survey and data sorting: Upon receiving the design task, the designer should visit the site of the project, and sort out the existing CAD drawings, laying the basis for importing them into SketchUp and subsequent design.

Conceptualization and sketch design: The field survey is followed by the sketch design. In this phase, the designer can design the landscape using the freehand tool in the Sketchup interface, based on his/her intuitive feeling and understanding of the site environment. To clarify the landscape effect and spatial organization relationship, the designer can construct a spatial model of the design plan on SketchUp. The spatial 
model can magnify the defects of the plan, so that the designer can make in-depth adjustments and modifications.

Plan modification and completion of the preliminary plan: The complete landscape design plan should include the general layout, the panoramic perspective drawing, the greening map, etc. These drawings can be completed with the aid of SketchUp software. Meanwhile, all drawings should be saved and converted to the required format before finalizing the preliminary plan.

Review of the preliminary plan and feedbacks: The preliminary design plan should be submitted to Party A for review, which will usually require some modifications. Thus, the landscape design plan cannot be finalized without multiple rounds of modifications. This gives full play to the SketchUp function of rapid customized modification.

Plan expansion and preparation of construction drawing: The model can be modified in individual groups to eliminate the impacts on other groups. There are two ways to prepare the construction drawing: marking the texts and figures directly in the SketchUp model, forming an intuitive and easy-to-understand drawing; exporting the general layout from SketchUp and preparing the drawing in CAD interface.

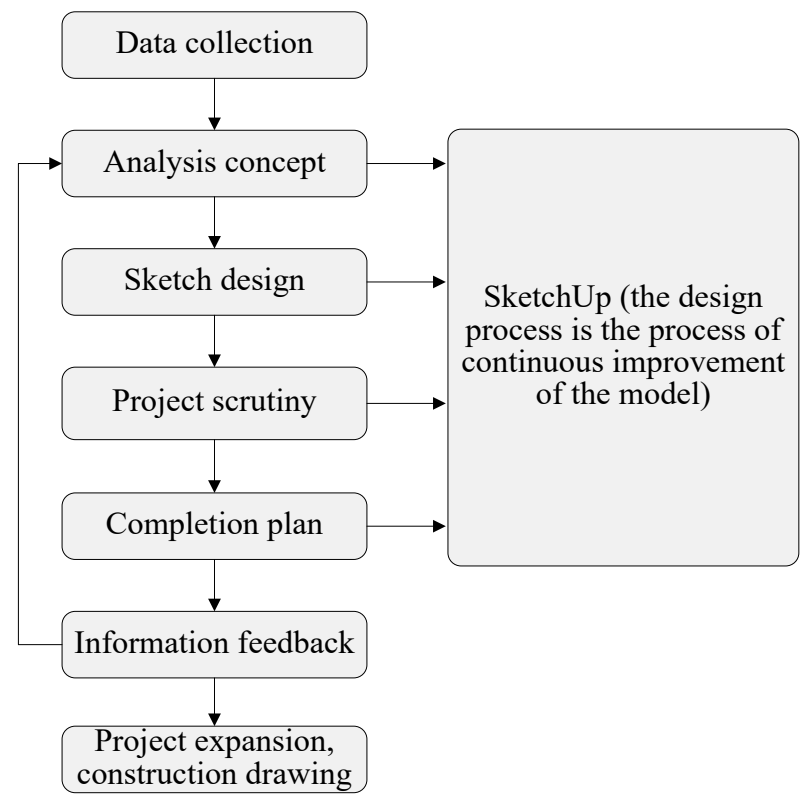

Fig. 7. SketchUp landscape design process

Figure 8 presents the students' design drawings on a garden landscape square after 18 hours of practical teaching. Obviously, the students basically fulfilled the requirements in the SketchUp syllabus. However, they failed to fully master the basic operations in actual application, could not skillfully apply the operation methods in landscape design, and had a poor macroscopic understanding of landscape design. To 
solve these defects, the students need to expose themselves more frequently to landscape design practices, such as practicing repeatedly in spare time.

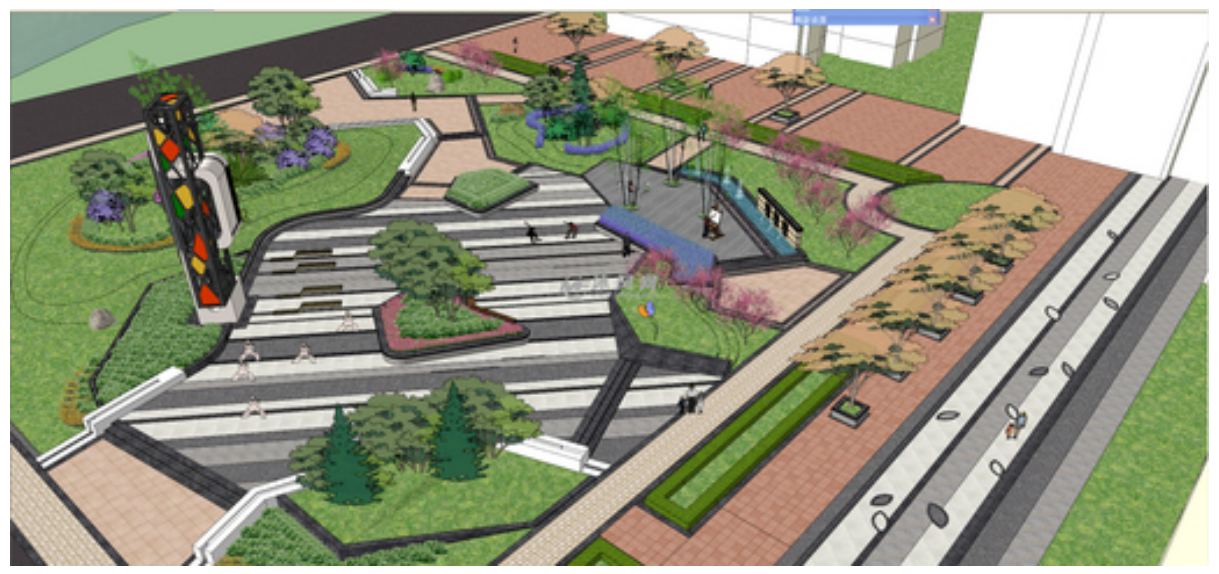

Fig. 8. Garden square design

\subsection{Suggestions on CAD teaching software in landscape design teaching}

To improve the students' practical ability and master the relevant software of landscape design, it is suggested that the teaching should be based on actual projects and be implemented in four steps.

Firstly, the teacher should demonstrate the procedure CAD landscape design.

Secondly, the students should repeat the operation steps, while the teacher should correct their mistakes; the teacher should explain the entire operation procedure, and ask the students to implement the specific steps.

Thirdly independently and complete the task, and improve the design plan according to the teacher's comments. Figure 9 presents the workflow of the landscape design based on our project teaching method.

Finally, the students should operate the software.

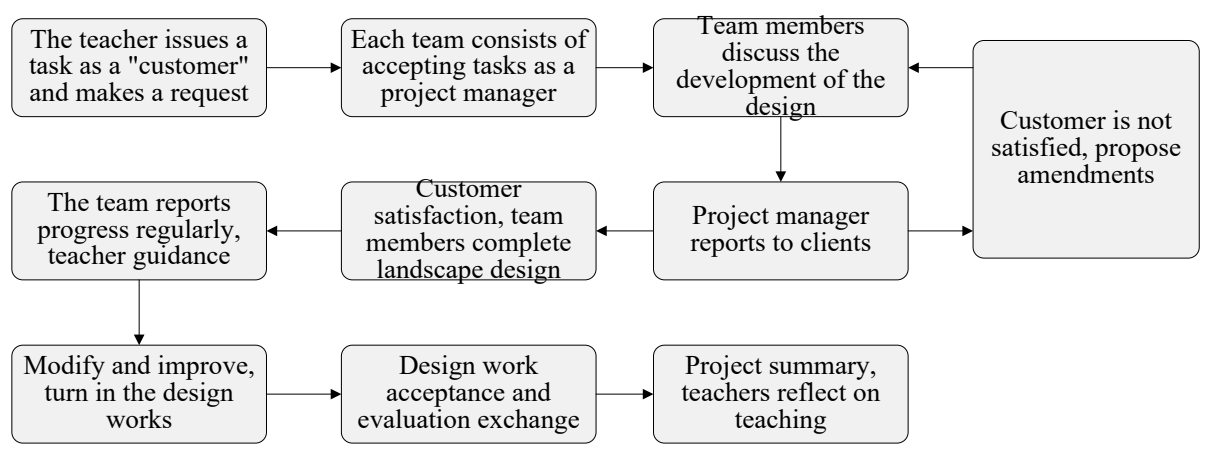

Fig. 9. Project teaching method for the specific process of landscape design 


\section{Conclusion}

In this paper, three CAD teaching tools were selected, namely, AutoCAD, 3D Max and SketchUp, and subjected to theoretical analysis and teaching practice. The main conclusions are as follows:

In terms of theoretical teaching, the functions of the three popular CAD teaching software were introduced, as well as their specific roles in landscape design.

In terms of practical teaching, the project teaching method and situational teaching method were adopted. Taking SketchUp as an example, the specific process of landscape design was summarized, followed by the application of SketchUp-aided practical teaching of landscape design.

In addition, the author put forward some suggestions on the teaching method for the application of CAD software in landscape design teaching.

\section{$5 \quad$ References}

[1] Mitsch, W.J. (1992). Landscape design and the role of created, restored, and natural riparian wetlands in controlling nonpoint source pollution. Ecological Engineering, 1(1-2): 2747. http://dx.doi.org/10.1016/0925-8574(92)90024-v

[2] Cai, H., Wang, Y., Li, Y. (2012). Research and development based on interactive computer aided instruction software. IERI Procedia, 2: 420-424. http://dx.doi.org/10.1016/j.ieri.2012.06.110

[3] Hutmacher, D.W., Sittinger, M., Risbud, M.V. (2004). Scaffold-based tissue engineering: rationale for computer-aided design and solid free-form fabrication systems. Trends in Biotechnology, 22(7): 354-362. http://dx.doi.org/10.1016/j.tibtech.2004.05.005

[4] Verroust, A., Schoneck, F., Roller, D. (1992). Rule-oriented method for parameterized computer-aided design. Computer-Aided Design, 24(10): 531-540. http://dx.doi.org/10.1016/0010-4485(92)90040-h

[5] Jackson, L.E., Hilborn, E.D., Thomas, J.C. (2006). Towards landscape design guidelines for reducing lyme disease risk. International Journal of Epidemiology, 35(2): 315. http://dx.doi.org/10.1093/ije/dyi284

[6] Simmons, M.T., Venhaus, H.C., Windhager, S. (2007). Exploiting the attributes of regional ecosystems for landscape design: the role of ecological restoration in ecological engineering. Ecological Engineering, 30(3): 201-205. http://dx.doi.org/10.1016/j.ecoleng.2007.01.007

[7] Mladenoff, D.J., White, M.A., Crow, T.R., Pastor, J. (1994). Applying principles of landscape design and management to integrate old-growth forest enhancement and commodity use. Conservation Biology, 8(3): 752-762. http://dx.doi.org/10.1046/j.1523$1739.1994 .08030752 . \mathrm{x}$

[8] Wang, W., Li, C.Q. (2003). Investigation on landscape design for urban river. Journal of Hydraulic Engineering, 34(8): 117-121. http://dx.doi.org/10.3321/j.issn:05599350.2003.08.023

[9] Vanderzanden, A.M. (2010). Reflective writing as an assessment for student analysis and synthesis ability in a landscape design course. Horttechnology, 20(4): 668-671. http://dx.doi.org/10.4174/jkss.2011.81.1.25 
[10] Menulty, J.A., Halama, J., Dauzvardis, M.F., Espiritu, B. (2000). Evaluation of web-based computer-aided instruction in a basic science course. Academic Medicine, 75(1): 59-65. http://dx.doi.org/10.1097/00001888-200001000-00016

[11] Lynch, T.G., Steele, D.J., Johnson, P.J.E., Lacy, N.L., Duffy, S.W. (2001). Learning preferences, computer attitudes, and test performance with computer-aided instruction. American Journal of Surgery, 181(4): 368-371.http://dx.doi.org/10.1016/s0002-9610(01)00575-x

[12] Wang, P., Chan, P.S. (1995). Advantages, disadvantages, facilitators, and inhibitors of computer-aided instruction in singaporel"s secondary schools. Computers \& Education, 25(3): 151-162. http://dx.doi.org/10.1016/0360-1315(95)00048-8

[13] Chowdhury, B.H, Clark, D.E. (1992). COPERITE-computer-aided tool for power engineering research, instruction, training and education. IEEE Transactions on Power Systems, 7(4), 1565-1570. http://dx.doi.org/ 10.1109/59.207381

[14] Lee, S., Yan, J. (2016). The impact of $3 \mathrm{~d}$ cad interfaces on user ideation: a comparative analysis using sketchup and silhouette modeler. Design Studies, 44: 52-73. http://dx.doi.org/10.1016/j.destud.2016.02.001

\section{Authors}

Wenbo Jiang received his degree of Master of Fine Arts in 2012 from Yanshan University. After graduation, he has been a lecturer at Hebei University of Environmental Engineering. His main research interests include public art and art education.

Yuan Zhang received her B.Sc. degree in 2009 from social work in Taiyuan University of Science and Technology; M.Sc. degree in 2012 from sociology in the University of Science and Technology Beijing. Her main research interests include teaching management and social security.

Article submitted 2019-01-15. Resubmitted 2019-02-28. Final acceptance 2019-03-03. Final version published as submitted by the authors. 